\title{
Leadership practice as interaction in primary care emergency team training.
}

Accepted version to be published in Action Research, vol 13, No.1 2015, USA, Sage journals

\begin{abstract}
The present study, framed as critical action research, aimed at contributing to the improvement of training emergency teams in primary care. The first author was a participating observer in local simulation sessions performed by ten different teams. Leadership practice as interaction was analysed in three types of communicative spaces: in the review and debriefing sessions; in the author group; and in focus groups involving local stakeholders. The teams practiced both designated and distributed leadership in the course of the various training sessions. During the simulation sessions, the teams remained aware of the physicians' formal responsibility for decisions concerning diagnosis and medication. Shifts in leadership modes coincided with situational changes requiring particular competencies. Distribution of leadership and teamwork dynamics were informed by simple, yet fundamental principles: strong commitment to the task at hand even though "unreal"; responsibility for the patient's life and health; responsibility for the colleagues' functioning and well-being; and, a perception of calmness as an indicator of good teamwork. A rising awareness with regard to leadership practice as interaction was facilitated by critical application of theory and engaged participation of local personnel in several analytical phases.
\end{abstract}

\section{Introduction}

In medical emergency teams, the main research focus regarding leadership has been on the emergence of a designated leader and that person's performance while leading (Härgenstam, Lindkvist, Brulin, Jacobsson \& Hultin, 2013; Roberts et al, 2014; Skog et al., 2012), with less attention being focused on interplay between the leader and other team members. While emergency team leadership has been studied in hospital settings (Bristowe et al., 2012; Ringen, Hjortdahl \& Wisborg, 2011; Sarcevic, Marsic, Waterhouse, Stockwell, \& Burd, 2011), evidence accumulated in primary care settings is scarce. In Norway, primary care emergency teams usually include a General Practitioner (GP), paramedics and nurses, and are constituted "ad hoc" (Hunziker et al., 2009). Regulations require that the training of such teams focus on interaction (Ministry of Health and Care Services [MHCS], 2005). The team's constitution and work is informed by local conditions (Brandstorp, 2009; Forland, Zakariassen, \& Hunskar, 2009). Physicians are, however, explicitly mandated to take responsibility for decisions concerning diagnosis and treatment whenever partaking in a team (MHCS, 1999).

In an overview of identified team KSAs (knowledge, skills and attitudes), team leadership was the first dimension listed (Baker, Salas, King, Battles, \& Barach, 2005). In medical education, a newer definition of teamwork dimensions and behaviours includes reference to: "appropriate assertiveness, decision-making, situation assessment, leadership, and 
communication." (Wright et al., 2009, p.32). It states that, "Team leadership can be shown by several team members", and includes elements such as: explain to others what is expected from them, listen to their concerns, provide statements of direction, strategy, and/or priorities for the task, set goals, and provide feedback.

There remains, however, a general dichotomy between leader-centred theories, focusing on the single ("heroic") person as leader, and theories emphasising functions, or roles, and how both the followers and the designated leader are essential to leadership practice ("postheroic”) (Barker, 2001; Kellerman, 2008; Sørhaug, 1994; Trillingsgaard, 2010; Wang, D., Waldman, D.A. \& Zhang, Z. 2013). In 1954, C. A. Gibb introduced the concept of "Distributed leadership": "Leadership is probably best conceived of as a set of functions which must be carried out by the group" (Gibb, 1968, p.94). "Distributed leadership in practice" has been described by J.P. Spillane (2005) as the interactions between people in a particular context, underlining that this differs from a predetermined, organisationally structured sharing of tasks or responsibilities. Wang et al (2013) equate the terms shared leadership, collective leadership and distributed leadership and find "substantial empirical support to a positive relationship between shared leadership and team effectiveness" (p.12). Yet, a collaborative approach to leadership practice seems to represent a challenge within traditional healthcare (Lingard et al., 2012).

The aim of our study was to explore and develop appropriate training of different, local primary care emergency team. To that end, we investigated a series of differentiated team training sessions; first together with the local participants; then in a multidisciplinary research group; and finally, in local focus groups. A training session included an initial review and two realistic simulation sessions, each followed by a debriefing session. The role of the patient in these sessions has been studied previously (Brandstorp, Kirkengen, Halvorsen, Sterud, \& Haugland, 2012). The present paper investigates leadership practice; how this was constituted, enacted, and reflected upon in order to make local improvements. We also investigated whether - and in case how - our analyses of these local participatory processes were able to challenge the participants understanding of own practice when enriched by theory.

\section{Theoretical and methodological framework}

Our study was carried out within a framework of action research (AR) (Carr \& Kemmis, 1986; Kemmis, McTaggart, \& Nixon, 2014; Reason \& Bradbury, 2008), leaning more to the critical than the pragmatic AR orientation (Johansson \& Lindhult, 2008) by means of the researchers' introduction of theory in order to challenge the participants' assumptions with regard to their own practice. Effective learning, and thus change, may occur when group members challenge personal beliefs, in familiar contexts (Stocker et al, 2014). Aims in critical participatory action research are: "to help participants to transform (1) their understandings of their practices; (2) the conduct of their practices; and (3) the conditions under which they practice" (Kemmis et al., 2014, p.67). Understanding, the explicit focus of change in the present study, form the basis from which the participants may change the way their practice is conducted as well as local conditions in unpredictable, non-linear fashions. With reference to 
Habermas, Gustavsen (2001) claims that knowledge from a discourse on theory and a discourse on practice need a mediating discourse about how to link these. A variety of "Communicative Spaces" (the time, location and opportunity to reflect; Kemmis et al., 2014) served as one mediating connection between theory and practice (Jagosh et al., 2012; Waterman, 2007). The debriefing sessions in the explored training model, constituted a major communicative space where all participants were asked to share their observations and reflections, free from checklists and other limitations on learning objectives, and facilitated by the first author. Another space was created by inviting all participants to take part in focus groups to discuss the results of a preliminary analysis of the material. The access to these communicative spaces was facilitated by long-standing professional relationships between the first author and several of the local nurses, paramedics and GPs, and with the multidisciplinary research group (Wicks \& Reason, 2009). The local GP and PhD, PAH, participated both in the local training and in the research group, which also comprised a paramedic, BH, an anesthesiologist, BS, a professor of General Practice, ALK and a former rural GP, HB. The latter had participated in developing the team training model during 200308, at times together with instructors in the study, applying an action learning approach (Doyle, 2014) with group reflections and a dialogue meeting.

Our analyses are informed by theories of hermeneutics, phenomenology and complex adaptive systems. A core concept of hermeneutics, which also accords with guiding principles of action research, is the "evolving spiral of comprehension". As we alternate between focusing on the parts and on the whole, new insights emerge dialogically, creating a constantly broadening "situated horizon," one that may both challenge our prejudices and enhance our comprehension (Gadamer, 1989). This spiral pattern of interpretation recurs in various phases in the study, such as: 1) when the participants explore parts of the training during debriefings in light of their experience of the session as a whole; 2) when a current session is seen to be mirrored in similar experiences; 3) when an individual transcript of a debriefing is compared to those of all other sessions; 4) when local participants discuss a preliminary analysis of a particular session against the background of the team's work in general; 5) when these reflections are integrated into the advanced analysis of all the material;6) when this analysis is integrated into theoretical frameworks; and, lastly, 7) when changes are made in local practice.

The term "abduction", which is closely related to hermeneutics and the spiral of comprehension, denotes an analytical process essential to reflexive methods within qualitative research (Alvesson \& Sköldberg, 2009). Abduction is characterised by an interplay between empirical observation and theory that enhances our understanding of the case under study in a spiralling manner. By means of reflections-on-action (Schön, 1983), new ideas and knowledge emerge from the analyses provided by participants both close to and at a distance from practice, with the empirical field as the starting point (Atkinson \& Delamont, 2005). As indicated above, this occurs during local team training, within the research group and in local focus groups, and helps us approach phenomena in a variety of ways that allow the exploration of patterns and deep structures. 
Phenomenology provides the theoretical framework that facilitates close examination of personal experience, in this instance, of the participants' subjective life-world of professional work within their familiar contexts (Alvesson \& Sköldberg, 2009). Finally, we find the concept termed "Complex Adaptive Systems" (CAS) relevant to healthcare (Greenhalgh, Plsek, Wilson, Fraser, \& Holt, 2010; Kernick, 2004; Plsek, 2001; Plsek \& Wilson, 2001; Plsek \& Greenhalgh, 2001; The Health Foundation, 2010). CAS offers a model for qualitative studies of persons participating in dynamic, non-linear, non-mechanical processes while maintaining sustainable groups (Mennin, 2007). Changes in one element of the process alter unpredictably the context for all other elements (Campbell, 2004). Positive feedback processes, a circular type of causality, are essential to the process as a whole (Juarrero, 2000). In addition, all interactions are focused around the system's "shared vision" or rules, termed "attractors". Adaptation occurs regularly, but when CAS become chaotic, the attractors may "bifurcate" and transform into new patterns of attractors as the system self-organises (Campbell, 2004; Eidelson, 1997; Sturmberg, O'Halloran, \& Martin, 2012).

\section{Material}

The first author participated in team training sessions on ten separate days (May 2010 to May 2011) in Alta, a rural municipality in Northern Norway. She acted as a participating observer during each training, which consisted of an initial review and two simulation sessions each followed by a debriefing session. This took place in the primary care emergency clinic where the participants work, without any additional equipment. The various teams were typically comprised of one or two GPs, one or two nurses, two to four paramedics, and, on some occasions, medical and paramedic students, thus reflecting realistic ad hoc teams.

\section{Initial reviews}

Under the leadership of a local GP instructor and a paramedic instructor, the initial two-hour reviews covered the basic principles of the treatment of traumatised patients, smaller collaborative exercises and the opportunity to reflect on previous experiences. In addition, the team received instruction in essential elements of teamwork, such as closed-loop communication, wherein received information is explicitly confirmed, and addressing each other by names. The role of team leader was rarely assigned explicitly, but rather assumed by one of the participating GPs.

\section{Simulation sessions}

The teams organised themselves for the simulation sessions. One of the instructors usually simulated a severely injured or ill patient or, at times, an acquaintance or the parent of an injured or ill baby (mannequin). Almost all scenarios were time-critical, challenging, run in real time, and enacted as realistically as possible. For example, a team would drive out to a person lying by the side of a road, provide breathing assistance, place the patient in the ambulance, insert IV-lines, and "report" to the hospital and clinic. In other simulations, patients were found indoors - in a waiting room or on a staircase. In most sessions, the ambulance drove to the primary care emergency clinic where the nurses prepared for the 
patient's arrival, sometimes along with a GP. One physician always joined the paramedics in the ambulance in order to examine the patient as early as possible. The instructors closed the simulation session once the patient was deemed ready for transport to the hospital, typically after approximately half an hour of simulation.

\section{Debriefing sessions}

In the debriefing session following each simulation, the person having simulated the patient ( or parent) participated in a mixed role of subject, instructor and colleague. To ensure a consistent focus group process based on equity, the first author was present at all 19 of these sessions, acting as the facilitator of 16 of them. All members were asked to reflect upon three questions in three rounds: a) "How did you experience the simulation session?"; b) "What went well?"; and, c) "What could have been handled differently?" Each debriefing session lasted 45-60 minutes. Stocker et al. (2014) recommend two phases during the debriefing session; a critical reflexive observation and abstract conceptualisation phase. In the model we explored, these are braided.

The first author made field notes during the simulations and the initial reviews. The debriefing sessions were tape-recorded and the first author transcribed them, consecutively and verbatim. A few of the initial debriefings were co-conducted by an assistant who later left the project. The second training in the study consisted of only one simulation and debriefing due to insufficient time control. As one of the recordings was incomplete due to technical problems, the total of 19 recorded debriefings yielded 18 complete transcripts.

\section{Two focus groups}

The materials for the study were enriched by transcripts of two tape-recorded focus group sessions. Comprised of voluntarily registered local professionals, both lasted nearly two hours and were facilitated by the first author. These groups reflected upon preliminary findings relating to leadership practice. The debriefing transcripts revealed that even the experienced nurses in the teams tended to speak less than the paramedics and the physicians. Consequently, the first group included only two nurses, and they had the lead in the conversation. The second group was comprised of three experienced paramedics and three young physicians together, due to their formerly observed tendency to share leadership. Two of these persons were also instructors, one from each profession. This conversation was to a greater extent than the previous, guided by the facilitator.

\section{Analysis}

In order to explore how leadership practice unfolded during the sessions, abductive approaches as described above, were applied. The review session was merely described, based both on the first author's observations and on discursive elements emerging from the two local focus groups. The transcripts of the reflections in the debriefings were scrutinised by applying a dual perspective: first, how leadership practice was enacted in the debriefings, and, second, how leadership in the simulation sessions was reflected upon. In accordance with the hermeneutical spiral of comprehension and abduction, the investigations continually 
alternated between the complete set of transcripts and on individual parts, focusing, for example, on word sequences or even single word usages. Each of these steps informed the next. First, the authors, separately, identified common-sense themes in the transcripts, characterising leadership practice as interaction; these proved to be both many and heterogeneous. Initially, three of the authors focused on how the emergence of a leader and that leader's performance generated interaction, while the others focused on aspects of shared or distributed leadership. This dichotomy, paralleling the dichotomies within leadership theory, was then transcended, with two main categories being established: designated and distributed leadership practice. We also identified categories of statements indicating the actions of the participants (Box 1), and explored these with respect to patterns of leadership, either explicit or implicit.

\section{Box 1. Perspectives on the participants' actions during days of team training:}
a) they had become integrated members of the team,
b) they enacted their particular skills,
c) they contributed their professional knowledge while simulating and debriefing,
d) they invested effort in striving to save the patient's life,
e) they perceived the interplay they were a part of,
f) they contributed to leadership practice during the shifting phases of the day.

Applying a Microsoft Word processing tool, we sought for patterns in the use of linguistic elements having connotations about leadership practice. The first group of word stems, relating to comments in the transcripts, were: "lead", "overview" and "control". This motivated us to then count a group of word stems assumed to be linked to leadership in general: "decide", "determine", "conclude" and "consider". Finally, we quantified the use of the term "calm" as connected to the participants" reflections on good teamwork, and the word "report" regarding a particular action characterising good leadership practice. All findings were continuously controlled for consistency of meaning in the context of the debriefings. The preliminary results of the researchers' analyses were then discussed in the two focus groups in Alta, followed by a content analysis of the transcripts of these group discussions. These spirals, moving from the empirical to the analytical and on to validation, which are at the core of action research and in accordance with the principles of abduction, enriched the data and deepened our insight into leadership practice as interaction.

\section{Results}

We found varying types of leadership practice: designated leadership carried out in an informative manner during the review, and both designated and distributed leadership 
manifested during the scenario trainings and the debriefings. The extent to which the leadership was distributed, however, varied with the purpose and nature of the setting. The review was pre-structured, as regards both time and topics, and controlled by the instructors in a friendly and relaxed manner. All of the participants followed them as leaders, apparently confident of their competence and benevolence. The style of leadership displayed during this part of the training day may be characterised as designated, non-authoritarian, and securing of a calm atmosphere.

In the simulations sessions, the instructors maintained their designated leadership only initially, while gathering the group and announcing the selected scenario. During the simulations, however, distributed leadership was exercised within the teams. This was apparent to the participating observer and was also validated in the debriefings.

GP6: Especially at the location, I noticed that they [the paramedics] took the lead somewhat, together with you [looks at the younger GP].

[..]

GP6: I think they [the paramedics] made clear suggestions and they provided clear feedback. She [the GP] was clear and very orderly when she arrived with the patient, explained the scenario, her examinations, and their results.

Although they consistently gave wider responsibility to the GP - as a designated team leader - the team members acknowledged during the debriefing that they themselves had actively sought to keep an overview and to help maintain control. They had given instructions to others, and had at times made decisions for the entire group, especially during scenarios taking place outside the emergency room. One specific element of leadership practice was, however, always expected of the GP: the report briefing the team upon arrival at the local emergency room. The GP's situational interpretations would involve both an overview and advanced medical insight, which was presumed and acknowledged by all participants.

In almost every debriefing session one of the instructors initiated a discussion, thereby taking over the lead in the conversation temporarily. Although both the observing instructor and the instructor simulating a patient did this in equal number of times, greater engagement was evoked by the simulated patient. The paramedics, physicians and nurses also did this, but only occasionally. In general, taking the lead of the conversation, was precipitated by a statement or a question that caught the others' interest. Still, the first author, the designated leader in these sessions, did not let these digressions interfere with the structured, three rounds of questions established as the format. In short: the pattern in the debriefings resembled the pattern in the simulations, manifesting both designated and distributed leadership.

In the interpretations of the transcripts regarding team collaboration, a broad spectrum of perceptions and emotions within the teams is revealed. The physicians tended to focus on medical issues, improvements of the group efforts as a whole, and to be self-critical. The paramedics tended to focus on how to handle the patients and the equipment, and spoke positively about the efforts of the group as a whole while being less self-critical. The nurses 
tended to reflect on their own defined working tasks, but also on how they served the group as a whole, such as in this example ( $\mathrm{N}=$ nurse).

N11: You just have to "read" what is going on, and ask a bit carefully: "Should I measure the blood pressure?"

The cooperation in the teams ranged from conflict, uncertainty and discomfort at one pole of the continuum to calmness, consent, and satisfaction at the other. No training session was without tension and doubt. This suggests that the scenarios were close to reality, highly demanding, and engendering the high level of alertness or even distress that can generally be expected in actual emergency settings. The statements had certain traits in common (Box 2), what could be termed "attractors" in the language of complexity theory.

\section{Box 2. The members' displayed actions categorised according to some simple rules or attractors:}
a) strong commitment to the task at hand, even though "unreal",
b) high awareness of responsibility for the patient's life and health
c) mutual concern for the colleagues' functioning and well-being,
d) perception of calmness as an indicator of good teamwork.

Our analysis of the linguistic patterns showed, that the word-stems "control", "lead", and "overview" were used frequently by all the participants (Table 1), with connotations relating to on-going processes. This is evident in the following dialogue commenting upon the GP being unexpectedly prohibited from participating in the simulation. ( $\mathrm{Pa}=$ paramedic):

Pa17: The doctor should probably have come too.

Pa18: Yes, she should have joined us.

Pa17: Yeah, she should definitely have been with us.

Pal8: Yeah, she should have done the steering.

Pa17: Yeah.

Pa18: Had an overview.

Pa17: Yeah.

Pal8: This time I had to...

Pa17: This time you did the steering she should have done.

The words "determine", "decide", and "conclude", all representing a finalising stance, were hardly used at all. On the other hand, the word "consider" was used frequently by all team members, except the nurses. Words denoting "calmness" followed yet another pattern, clearly being a central focus of the nurses' attention while debriefing and during later discussions. They depicted calmness as benefitting the patients as well as the team in general and themselves in particular. All participants consistently emphasised the significance of a calm atmosphere throughout the team training days. This was interpreted as indicative of people 
knowing and respecting each other's competence, and recognising that the contribution of each person matters in such settings. Calmness - as opposed to shouting or assuming an authoritarian leadership style - was referred to as being facilitative for the interactions among all participants;

Pa 5: You know what to do, and when you focus on that, everything is easier - and calmer. Feeling comfortable with the people you work with also plays a positive role.

This might rub off on the patient too.

One simulation session was interrupted by a nurse, due to lack of calmness. Her main concern was that the stress created by authoritarian leadership style was detrimental to a constructive use of the team's collective competence.

Table 1. Count of words linked to leadership used in the debriefings, according to profession

\begin{tabular}{|c|c|c|c|c|c|c|c|c|c|c|}
\hline Search round & First & First & First & Second & Second & Second & Second & Third & Third & \\
\hline Words & Lead & Control & Overview & Consider & Decide & $\begin{array}{l}\text { Determi } \\
\text { ne }\end{array}$ & $\begin{array}{l}\text { Conclud } \\
\mathrm{e}\end{array}$ & $\begin{array}{l}\text { Report } \\
\text { (tool) }\end{array}$ & $\begin{array}{l}\text { Calm } \\
\text { (result) }\end{array}$ & $\begin{array}{l}\text { Use in } \\
\text { total }\end{array}$ \\
\hline Instructors & 31 & 27 & 19 & 23 & 3 & - & 4 & 23 & 40 & 170 \\
\hline Researchers & 54 & 12 & 9 & 1 & 3 & 1 & - & 12 & 21 & 113 \\
\hline Physicians & 29 & 27 & 26 & 17 & 2 & 1 & 4 & 15 & 34 & 155 \\
\hline Paramedics & 17 & 28 & 9 & 12 & 3 & - & 1 & 14 & 26 & 110 \\
\hline Nurses & 8 & 14 & 12 & 3 & - & - & 1 & 6 & 30 & 74 \\
\hline Total & 139 & 108 & 75 & 56 & 11 & 2 & 10 & 70 & 151 & 622 \\
\hline $\begin{array}{l}\text { Local } \\
\text { Participants } \\
\text { (excluding } \\
\text { Researchers) }\end{array}$ & 85 & 96 & 66 & 53 & 8 & 1 & 10 & 58 & 130 & 507 \\
\hline
\end{tabular}

Our preliminary findings of leadership practice as interaction, manifesting both distributed and designated leadership, were received differently by the two focus groups. The nurses responded positively at once, while the concept of leadership distribution was not immediately accepted by the group of physicians and paramedics. Initially, they focused strongly on the designated leader, though modifying their view during the discussion. One young physician was a proponent of shared leadership based on competence. Another young GP stressed the importance of sharing her or his understanding of the situation with the whole team during tense and ambiguous situations, primarily to get the others to follow her/him:

GP1: If you have a very good plan or idea of how to implement something, you have to be able to convey it too, for the others to buy your ideas.

The paramedics stated that they would intervene if the physician lacked skills or an overview. Both nurses and paramedics expressed frustration when uncertain as to whether or not a 
physician would be available. The physicians' presence was expected to ensure a safe and calm atmosphere. They were also needed to authorise the prescribing of medication. No one objected to the physician being a team leader. Yet, the paramount topic in the focus groups was that functioning together in the best interest of the patients must override formal structures.

\section{Discussion}

Through participatory exploration of leadership practice in local team training, we challenged the local health personnel in their understanding of leadership practice. In line with other participatory AR projects (see Bish et al,, 2013 or Mackoff et al., 2013 ) we aimed at developing local leadership practice based on local theory/practical knowledge. Following the critical tradition, we also explicitly challenged the participants' understanding by means of enriching our analyses with acknowledged theories before sharing them with local focus groups. Effective learning, and thus change, craves certain premises: that individuals and group members alike challenge their personal beliefs in familiar contexts while training in teams. (Stocker et al., 2014)

Our study revealed both designated and distributed leadership, shifting in response to the competencies that were either required or available (Gibb, 1968, Spillane, 2005). This result accords with a post-heroic concept of team leadership, described by Norwegian organisational researcher J. K. Arnulf (2012) as follows: "Leadership, understood as the ability to make decisions and to influence others, is alternating. The most competent person in a particular situation at a given point will gain most influence" (p.72). As demonstrated in the second focus group, actual leadership practice differs from what is commonly perceived. This is supported by Spillane, Camburn, Pustejovsky, Pareja, and Lewis (2008), who observed that how leadership apparently was distributed, changed when shifting focus from who influenced whom to how followers and leaders themselves explained the leadership practice within their own organisation.

The investigated ad hoc teams manifest some of the strong relationships characterising what Arrow et al (2010) describe as teams, less of the role-specific training in what they call crews, though even more of the temporality of task forces. A frequently applied definition of teams, however, supports the use of that term in the present study: "A team is a smaller number of persons with complementary skills who are committed to a common purpose, performance goals, and approach for which they hold themselves mutually accountable" (Katzenbach \& Smith, 2005, p. 45).

Such "common purposes, goals and approaches" accord with certain simple yet fundamental structures or rules, the so-called attractors in the CAS-concept, forming recognisable patterns of adaptable interaction and mutual responsibility (Plsek, 2001; Plsek \& Wilson, 2001). Three of the four attractors outlined in Box 2, were explicitly confirmed by the participants in the focus groups: a high awareness of responsibility for the patient's life and health; a mutual concern for their colleagues' functioning and well-being; and, a perception of calmness as an 
indicator of good teamwork. The fourth attractor, "strong commitment to the task at hand, even though "'unreal", seems to be confirmed implicitly by the steady local support, participation and development of the team training initiative since its beginning in 2007. Such overarching attractors, representing the team's collective ideal basis, may even be seen as a prerequisite for distributed leadership.

While there was always a designated leader, the extent to which the leadership also became distributed varied, in accordance with CAS theory, depending on the purpose and nature of the setting (Best, Greenhalgh, Lewis, Saul, Carroll, \& Bitz, 2012). CAS applies to socially adaptive, self-organising and dynamic systems. The teams were found to act in dynamic ways depending on the feedback from the other members and the patients. Although self-organised and adaptive, they never "bifurcated" due to chaos, thus necessitating the emergence of new deep structures and attractors (Goldstein, 1999). The attractors proved flexible, yet strong enough to stabilise each team as a whole during critical phases.

The participants' sense of leadership practice as interaction is supported by the linguistic patterns, both in word usage (Table 1) and discourse. We interpret the most striking pattern, the relative absence during the debriefings of the word stems "decide", "conclude" and "determine", as indicating an implicitly distributed rather than an explicitly designated team leadership practice (Table 1). Also, the use by all of word stems "control" and "overview" implied that they would not leave those functions solely up to the team leader (GP). Utilising the tools for providing an overview, or for sharing information while working in a team, may enhance a shared "situational awareness" (Fore \& Sculli, 2013), acquired through processes of situational assessment, one of the core dimensions of teamwork (Wright et al., 2009). Explorations in delivery room settings (Mackintosh, 2009) revealed that providing an overview on a visible whiteboard was one of three key elements facilitating such awareness The other two elements were coordinator and inter-professional "handovers".

An emphasis on calmness similar to that of our teams and focus groups, was also found in a study of teamwork during clinical emergencies, based on both inter-professional focus groups and simulations (Bristowe et al., 2012). In addition, it echoes certain elements in complexity theory, as formulated by McClure: "practicing patience in the midst of high anxiety and disorder is the most effective leadership tool for promoting group development" (McClure, 2005, p.104).

Phelps and Hase (2002) have shown that that there are several theoretical and methodological connections between complexity theory and open-ended action research (AR). These are also present in our AR study: the shared notion of the open, non-linearity of social systems; the nature of change as emergent; change as self-organised adaptation (hence no top-down master plan); the role of agent interaction (participation); inherent unpredictability of the situation and sensitivity to the context (hence training in a familiar setting); feed forward and feedback (reflexivity and communicative spaces); self-organisation and system stability (structural resistance to radical change); and points of change called bifurcations or phase transitions. 
The main strength of this study is the richness of the material and the diversity of participants, representing a variety of experience and contexts in which leadership was enacted. This ensured that the phenomenon of leadership practice as interaction could be explored at different levels and from a variety of perspectives. Four of the five authors had, in addition, used the team training model in other contexts and had numerous experiences of real-life emergencies (as GPs, as a paramedic and as a flight physician). We are aware that there may, however, exist certain limitations to the validity of our findings. For several years prior to the present study, the first author had been pivotal in developing the primary care team training model in that geographical study area, which may have influenced current local leadership practice. Furthermore, we do not know to what extent leadership practice in simulated sessions is representative of real life emergencies. However, the training in itself is a real life activity where leadership is needed. We have been able to study a setting that has succeeded in keeping this training on-going, consistently, over a period of more than seven years. Kemmis et al (2014) claim that the work in action research "must be considered legitimate and valid by the participants themselves". The steady local support to the training sessions, also with a researcher present, to the focus group interviews, and to public dissemination of early results, reveals this kind of validity and legitimacy. In line with the action research design, we contributed to a raised awareness of leadership practice amongst the local professionals involved in such trainings by "challenging their beliefs and habits", as recommended by Stocker et al. (2014) with regard to learning, and by Johansson and Lindhult (2008) with regard to emancipation and equity.

Previous studies have explored leadership in emergency teams mainly from a "heroic" leadership perspective. This was also the case in a study of lead physician style in rural primary care in Norway, performed by the use of focus groups and questionnaires (Hana, 2014). Our study adds to the understanding of leadership practice as interaction related to emergency teams, but it could also enrich the concept of leadership practice in primary care in general.

\section{Conclusion}

Our critical action research study investigated leadership practice as interaction during a series of full-day team trainings each involving a review, two challenging and realistic in situ simulation sessions, and debriefings sessions. The preliminary analyses undertaken by the research group, informed by leadership theory, were elaborated in two local focus groups. The primary care participants manifested both designated and distributed leadership through out the days. Shifts in leadership practice modes co-occurred with situational shifts requiring different competencies. During the simulation sessions, the teams remained aware of the GPs' formal responsibility for decisions concerning diagnosis and medication. The eventual distribution of leadership and the overall teamwork was guided by simple, yet fundamental principles, i.e. the system's "attractors" in the terminology of Complex Adaptive Systems, relevant in all settings: strong commitment to the task at hand, even though "unreal"; responsibility for the patient's life and health; responsibility for the colleagues' functioning 
and well-being; and, a perception of calmness as an indicator of good teamwork. The critical use of theory and participation of local health personnel in several analytic phases facilitated a new awareness of leadership practice.

\section{- $\quad$ Reference List}

- Alvesson, M. \& Sköldberg, K. (2009). Reflexive methodology: new vistas for qualitative research. London, UK: Sage.

- Arnulf, J. K. (2012). Hva er ledelse [What is leadership]. Oslo, Norway: Universitetforlaget.

- Arrow, H \& Henry, K.B. (2010). Using complexity to promote group learning in health care. Journal of Evaluation in Clinical Practice, 16, 861-866

- Atkinson, P. \& Delamont, S. (2005). Analytic Perspectives, in Denzin, N.K. \& Lincoln Y.S. The SAGE Handbook of Qualitative research. $3^{\text {rd }} \mathrm{ed}$.

- Baker, D. P., Salas, E., King, H., Battles, J., \& Barach, P. (2005). The role of teamwork in the professional education of physicians: Current status and assessment recommendations. Joint Commission Journal on Quality and Patient Safety, 31, 185-202.

- Barker, R.A. (2001). The Nature of Leadership. Human relations, 54, 469

- Best, A., Greenhalgh, T., Lewis, S., Saul, J. E., Carroll, S., \& Bitz, J. (2012). Large-system transformation in health care: a realist review. Milbank $Q .$, 90, 421-456.

- Bish, M., Kenny, A., \& Nay, R. (2013) Using participatory action research to foster nurse leadership in Australian rural hospitals. Nursing \& Health Sciences, 15, 286-291.

- Brandstorp, H. (2009). [Ambulance service and primary health care]. Tidsskr Nor Legeforen., 129, 2019.

- Brandstorp, H., Kirkengen, A.L., Halvorsen, P.A., Sterud, B., \& Haugland, Bjorgun. (2012). Training interaction in primary care teams: the role of the patient. The International Journal of Person Centered Medicine, 2, 4, 656-663.

- Bristowe, K., Siassakos, D., Hambly, H., Angouri, J., Yelland, A., Draycott, T. J. et al. (2012). Teamwork for clinical emergencies: interprofessional focus group analysis and triangulation with simulation. Qual.Health Res., 22, 1383-1394.

- Campbell, J., Flynn, J.D., Hay, J. (2003). The group development process seen through the lens of complexity theory. International Scientific Journal of Methods and Models of Complexity, 6, 1-33

- Carr, W. \& Kemmis, S. (1986), Becoming Critical: Education Knowledge and Action Research. Falmer Press, London and Philadelphia.

- Doyle L. (2014) Action learning: developing leaders and supporting change in a healthcare context. Action learning: Research and Practice, 11, 1, 64-71

- Eidelson, R.J. (1997) Complex Adaprtive Systems in the Behavioral and Social Sciences. Review of General Psychology, 1, 42-71

- Fore, A. M. \& Sculli, G. L. (2013). A concept analysis of situational awareness in nursing. J Adv.Nurs.69, $12,2613-21$

- Forland, O., Zakariassen, E., \& Hunskar, S. (2009). [Cooperation between ambulance personnel and regular general practitioners]. Tidsskr Nor Laegeforen., 129, 1109-1111.

- Gadamer, H. G. (1989). Truth and Method (2nd edn). London, UK: Sheed and Ward

- Gibb, C. A. (1968). Leadership: psychological Aspects. In D.L.Sills (Ed.), International Encyclopedia of the Social Sciences. New York: The Macmillan Company \& The Free Press.

- Goldstein, J. (1999). Emergence as a Construct: History and Issues, Emergence, 1, 49-72

- Greenhalgh, T., Plsek, P., Wilson, T., Fraser, S., \& Holt, T. (2010). Response to 'The appropriation of complexity theory in health care'. J Health Serv.Res.Policy, 15, 115-117.

- Gustavsen, B. Theory and Practice: the Mediating Discourse (2001). In P. Reason \& H. Bradbury (Eds), Handbook of Action Research. Participative Inquiry and Practice ( $p p X X-X X)$. Thousand Oaks SAGE

- Hana, J. (2014). The Clinician in Leadership. Perceptions of Style. Perspectives from Rural Primary Medicine in Norway. Ph.D. Thesis. UIT The Arctic University of Norway

- Härgestam, M., Lindkvist, M., Brulin, C., Jacobsson, M., \& Hultin, M. (2013). Communication in interdisciplinary teams: exploring closed-loop communication during in situ trauma team training. $B M J$ Open, 3. Rettrived from http://bmjopen.bmj.com/content/3/10/e003525.full

- Hjortdahl, M., Ringen, A. H., Naess, A. C., \& Wisborg, T. (2009). Leadership is the essential non-technical skill in the trauma team--results of a qualitative study. Scand J Trauma Resusc Emerg Med, 17, 48. 
- Hunziker, S., Tschan, F., Semmer, N. K., Zobris, R., Spychiger, M., Breuer, M., Hunziker, P. R., \& Marsch, S. C. (2009). Hands-on time during cardiopulmonary resuscitation is affected by the process of teambuilding: a prospective randomised simulator-based trial. BMC Emergency Medicine 9: 3.

- Jagosh, J., Macaulay, A. C., Pluye, P., Salsberg, J., Bush, P. L., Henderson, J., Sirett, E... \& Greenhalgh, T. (2012). Uncovering the benefits of participatory research: implications of a realist review for health research and practice. Milbank Q., 90, 311-346.

- Johansson, A. W., \& Lindhult, E. (2008). Emancipation or workability? Critical versus pragmatic scientific orientation in action research. Action Research 6, 95

- Juarrero, A. (2000). Dynamics in Action: Intentional Behavior as a Complex System. Emergence 2, 2, 2457.

- Katzenbach, J. R., \& Smith. D. K. (2005). The wisdoms of teams: creating the high-performance organisation. London, UK: McGraw-Hill.

- Kellerman, B. (2008). Followership: How Followers Are Creating Change and Changing Leaders. Harvard Business School Publishing India Pvt. Limited.

- $\quad$ Kemmis, S., McTaggart, R., \& Nixon, R. (2014). The Action Research Planner. E-book Springer

- Kernick, D. (2004). Complexity and the healthcare organizations: a view from the street. Oxon, UK: Radcliffe Medical Press Ltd.

- $\quad$ Lingard, L., Vanstone, M., Durrant, M., Fleming-Carroll, B., Lowe, M., Rashotte, J... \& Tallett, S. (2012). Conflicting messages: examining the dynamics of leadership on interprofessional teams. Acad.Med,, 87, 1762-1767.

- McClure, B. A. (2005). Putting a New Spin on Groups: The Science of Chaos. (2nd ed.) Mahwah, New Jersey: Lawrence Erlbaum Associates.

- Mackintosh, N., Berridge, E. J., \& Freeth, D. (2009). Supporting structures for team situation awareness and decision making: insights from four delivery suites. Journal of Evaluation of Clinical Practice, 15, 1, 46-54.

- Mackoff, B.L., Glassman, \& K. Budin, W. (2013). Developing a Leadership Laboratory for Nurse Managers Based on Lived Experiences. Journal of nursing administration, 43, 9, 447-454

- Mennin, S. (2007). Small-group problem-based learning as a complex adaptive system. Teaching and Teacher Education, 23, 303-310

- Ministry of Health and Care Services. (1999). LOV-1999-07-02-64. Act on Health Personnel.

- Ministry of Health and Care Services. (2005). FOR-2005-03-18-252. Regulation on demands for prehospital emergency medicine.

- Phelps, R., \& Hase, S. (2002). Complexity and action research: exploring the theoretical and methodological connection, Educational Action Research, 10, 507-524.

- $\quad$ Plsek, P. E. (2001). Appendix B. Redesigning Health Care with Insights from the Science of Complex Adaptive Systems. In I.o.M. Committee on Quality of Health Care in America (Ed.), Crossing the Quality Chasm: A New Health System for the 21 st Century. Washington D.C.: National Academy Press.

- Plsek, P. E. \& Greenhalgh, T. (2001). Complexity science: The challenge of complexity in health care. BMJ, 323, 625-628.

- $\quad$ Plsek, P. E. \& Wilson, T. (2001). Complexity, leadership, and management in healthcare organisations. BMJ, 323, 746-749.

- $\quad$ Reason, P., \& Bradbury, H. (2008). The SAGE Handbook of Action Research: Participative Inquiry and Practice. 2 nd ed.

- $\quad$ Ringen, A. H., Hjortdahl, M., \& Wisborg, T. (2011). Norwegian trauma team leaders--training and experience: a national point prevalence study. Scand J Trauma Resusc Emerg Med, 19, 54.

- $\quad$ Roberts, N., Williams, R.G., Schwind, C.J., Sutyak, J.A., McDowell, C. \& Griffen, D (2014) The impact of brief team communication, leadership and team behavior training on ad hoc team performance intrauma care settings. The American Journal of Surgery, 207, 170-178

- Sanchez J.A., \& Barach, P.R. (2012). High Reliability Organizations and Surgical Micro systems: Reengeneering Surgical Care. Surgical Clinics of North America, 92, 1-14

- $\quad$ Sarcevic, A., Marsic, I., Waterhouse, L. J., Stockwell, D. C. \& Burd, R. S. (2011). Leadership structures in emergency care settings: a study of two trauma centers. Int.J Med Inform., 80, 227-238.

- $\quad$ Skog, A., Peyre, S. E., Pozner, C. N., Thorndike, M., Hicks, G., \& Dellaripa, P. F. (2012). Assessing physician leadership styles: application of the situational leadership model to transitions in patient acuity. Teach.Learn.Med, 24, 225-230.

- $\quad$ Spillane J.P. (2005). Distributed leadership. The Educational Forum, 69, 143-150.

- $\quad$ Spillane, J. P., Camburn, E.M., Pustejovsky, J., Pareja, A. S., \& Lewis, G. (2008). Taking a distributed perspective. Epistemological and methodological tradeoffs in operationalizing the leader-plus perspective. Journal of Educational Administration, 46, 189-213. 
- $\quad$ Stocker, M., Burmeister, M., Allen, M. (2014). Optimisation of simulated team training through the application of learning theories: a debate for conceptual framework. BMC Medical Education, 14, 69

- $\quad$ Sturmberg, J. P., O'Halloran, D. M., \& Martin, C. M. (2012). Understanding health system reform - a complex adaptive systems perspective. J Eval.Clin.Pract., 18, 202-208.

- Sørhaug, T. (1996). Om ledelse. Makt og tillit i moderne organisering [About leadership. Power and trust in modern organisation] Oslo, Universitetsforlaget

- The Health Foundation (2010). Evidence scan: Complex adaptive systems. London, UK: The Health Foundation.

- Trillingsgaard, A. (2010). Udviklingsepisoder i ledelsesteam: ErhvervsPhD afhandling fra Aalborg Universitet. Aarhus: Udviklingskonsulenterne A/S.

- Wang, D., Waldman, D. A., \& Zhang, Z. (2013) A Meta-Analysis of Shared Leadership and Team Effectiveness. Journal of Applied Psychology. Advance online publication. doi: 10.1037/a0034531 Retrived from http://psycnet.apa.org/journals/apl/99/2/181/

- Waterman H., Marshall, M., Noble, J., Davies, H., Walshe, K., Sheaff, R., Elwyn, G. (2007). The Role of Action Research in Investigation and Diffusion of Innovation in Health Care: The PRIDE Project. Qualitative Health Research,. 17, 373-381

- Wicks, P.G., Reason, P. (2009). Initiating action research. Challenges and paradoxes of opening communicative space. Action Research, 7, 243-262

- Wright, M. C., Phillips-Bute, B. G., Petrusa, E. R., Griffin, K. L., Hobbs, G. W., \& Taekman, J. M. (2009). Assessing teamwork in medical education and practice: relating behavioural teamwork ratings and clinical performance. Med Teach, 31, 30-38. 